\title{
Article \\ Genetic Differentiation among Subspecies of Banksia nivea (Proteaceae) Associated with Expansion and Habitat Specialization
}

\author{
Jane Sampson and Margaret Byrne *
}

check for updates

Citation: Sampson, J.; Byrne, M. Genetic Differentiation among Subspecies of Banksia nivea (Proteaceae) Associated with Expansion and Habitat Specialization. Diversity 2022, 14, 98. https:// doi.org/10.3390/d14020098

Academic Editor: Hong-Hu Meng

Received: 19 December 2021

Accepted: 27 January 2022

Published: 30 January 2022

Publisher's Note: MDPI stays neutral with regard to jurisdictional claims in published maps and institutional affiliations.

Copyright: (c) 2022 by the authors. Licensee MDPI, Basel, Switzerland. This article is an open access article distributed under the terms and conditions of the Creative Commons Attribution (CC BY) license (https:// creativecommons.org/licenses/by/ $4.0 /)$.
Biodiversity and Conservation Science, Department of Biodiversity, Conservation and Attractions, Locked Bag 104, Bentley Delivery Centre, Perth, WA 6983, Australia; jane.sampson@dbca.wa.gov.au

* Correspondence: margaret.byrne@dbca.wa.gov.au

\begin{abstract}
Subspecies are traditionally defined using phenotypic differences associated with different geographical areas. Yet patterns of morphological and genetic variation may not coincide and thereby fail to reflect species' evolutionary history. The division of the shrub Banksia nivea Labill. into one widespread (B. nivea subsp. nivea) and two geographically localized subspecies (B. nivea subsp. uliginosa (A.S. George) A.R. Mast \& K.R. Thiele and B. nivea subsp. Morangup (M. Pieroni 94/2)) in south-west Australia has been based mainly on variation in leaf shape and pistil length, although flowering time and habitat differences are also evident, and subsp. uliginosa occurs on a different substrate. To assess the genetic divergence of $B$. nivea subspecies, we genotyped representatives from each subspecies for nuclear microsatellite and non-coding chloroplast sequence variation. We used distance and parsimony-based methods to assess genetic relatedness. Patterns were consistent with the existing taxonomy of subsp. nivea and uliginosa but not subsp. Morangup. Phylogenetic analyses revealed evidence for a more recent divergence of subsp. uliginosa associated with expansion from dryer sandy soils into the winter-wet ironstone soils in the southwest of Western Australia, consistent with progressive long-term climatic drying. Nuclear microsatellites showed low to moderate diversity, high population differentiation overall, and genetic structuring of subspecies in different biogeographical areas. We propose this pattern reflects the predicted impact of a patchy distribution, small populations, and restrictions to gene flow driven by both distance and biogeographic differences in subspecies' habitats.
\end{abstract}

Keywords: climate drying; cpDNA; ecotype; Evolutionarily Significant Units; gene flow; geographic expansion; patchy abundance; phylogeography

\section{Introduction}

Many recognized species are not genetically uniform and may be highly structured into historically isolated populations that may warrant consideration as intraspecific units [1] Taxonomically recognized subspecies are often based on geographically discontinuous morphological differences [2,3] or ecotypic differences [4]. Yet natural phenotypic or ecotypic diversity within species over wide distributions may not be consistent with genetic divergence representing the evolutionary processes within species [5,6]. Genetic divergence within species is influenced by gene flow [7] and affected by geographic (e.g., topography, distance) and environmental (habitat, climate, pollen, and seed dispersal) factors [8]. Although reciprocal monophyly is not expected for subspecies, some evidence of restricted gene flow between diverging taxa is expected in patterns of neutral genetic variation [6]. Given there are examples of lineage divergence associated with habitat specialization [9-12], widespread species containing subspecies that occupy different habitats might be expected to show genetic differentiation among habitats.

In Australian plant species, distinct population groups and divergent lineages have been identified within species of several genera that reflect disjunct and historically isolated 
population systems, geological and edaphic complexities, and contrasting habitats in terms of vegetation and climate [13]. Genetically distinct populations are particularly evident within species from the South-West Australia Floristic Region (SWAFR) [14,15] in a range of plant genera and families, including several in genera in Proteaceae, e.g., Banksia [12,16] and Hakea [17]. Taxonomic resolution can be challenging in this region as phylogenetic lineages often differ from phenotypic variation [17], and the prevalence of highly structured populations and divergent lineages highlights a need to recognize organized layers of genetic diversity below the species level [1].

Banksia nivea Labill. is a common and widespread non-lignotuberous, woody, evergreen, flowering shrub endemic to south-western Australia. There is considerable morphological variation in $B$. nivea mainly in pistil length, leaf size, and shape, and three subspecies are recognized with differing geographic extent [18]. The more common Banksia nivea Labill. subsp nivea is widespread but patchily distributed in dry sandy soil on sandplains, forests, and mallee from Eneabba in the north, southeast to Cape Arid. Subspecies Morangup (M. Pieroni 94/2) is an informally named subspecies, that is hypothesized to be a unique subspecies but has not been formally assessed or described. It has a highly restricted distribution as it is found at one location in the center of subsp. nivea's range. The rare subspecies uliginosa (A.S. George) A.R. Mast \& K.R. Thiele is also found in patchy populations in shrublands, woodlands, and forests, and is isolated from subsp. nivea and Morangup by $>100 \mathrm{~km}$. This subspecies has a limited distribution within a relatively rare, specific edaphic habitat of winter-wet ironstone in two areas on the coastal plain around Busselton and the Scott River in the southwest corner of Western Australia. It has a conservation status of endangered. A dated molecular phylogeny [19] suggests divergence of subsp. nivea and uliginosa during the Pleistocene ( $<2.5 \mathrm{Mya})$.

Unusually for Western Australia flora, B. nivea has adaptation to promote gene flow through seed dispersal. Infructescences of $B$. nivea are serotinous containing seeds with a delicate papery wing [20]. Although some follicles open to release seeds periodically, many remain on the plant for a long period of time. If plants die after a disturbance, mass recruitment occurs from the store of genetically diverse seeds held on the plant. Most recruitment occurs after a fire, and the removal of the foliage by fire enables effective wind dispersal of the released seeds [20].

The ecological characteristics of $B$. nivea have been well described [18,21], yet less is known of the species' reproductive biology. Flowers are yellowish-brown in subsp. uliginosa and cream-yellow-orange-pink/red-brown in subsp. nivea and subsp. Morangup, with a maroon-colored style and green pollen presenter; they have a mousey odor, and are well hidden within the plant $[18,22,23]$. Recent studies of subsp. uliginosa found that plants are self-fertile, and the mating system is predominantly outcrossed with pollination primarily by small non-flying mammals, e.g., honey possums, with some contribution from birds and insects [20,23]. Subspecies nivea and uliginosa flower between July and September and, although records are few, subspecies Morangup has been recorded to flower in April, June, August, and September [24]. Current flowering periods reported for all subspecies overlap (Western Australian Herbarium) suggesting that any gene flow between subsp. uliginosa and the other subspecies is more likely to be restricted by distance and environment rather than temporal isolation. A review of the Australian flora [25] found abundance and population disjunction to be strong determinants of the distribution of contemporary genetic diversity. Given the patchy abundance of $B$. nivea subspecies and the allopatric distributions of ssp. nivea and uliginosa in different biogeographic areas, we predict that there will be a significant genetic divergence between populations and subspecies. Analysis of the general pattern of genetic variation would provide a phylogenetic context for understanding subspecies relationships and their morphological and ecotypic variation, assist in consideration of the status of subspecies Morangup and provide information for the conservation of the rare subspecies.

Here, we surveyed four cpDNA sequences and 10 nuclear microsatellite loci from multiple individuals of each of the three subspecies of $B$. nivea in populations representative 
of the species' range to describe the pattern of genetic variation and assess whether it is reflected in the current taxonomy based on the phenotypic and ecotypic variation. Specifically, we address the following questions: (1) is there evidence of genetic structure in the range of $B$. nivea, and (2) are the phenotypically and ecotypic based subspecies reflected in the genetic relationships among populations within the species?

\section{Materials and Methods}

\subsection{Sampling and Genotyping}

Leaves were sampled from four to 20 adult plants in seven (subsp. nivea), one (subsp. Morangup), and 10 (subsp. uliginosa) populations from the ranges of the subspecies (Figure 1). Genomic DNA was extracted from lysed, freeze-dried leaf material following the CTAB-PVP method [26]. The chloroplast $p s b \mathrm{~A}-\operatorname{trn} \mathrm{H}$, ndhF, trnV, and $\operatorname{trn} \mathrm{Q}-r p s 16$ intergenic spacer regions were selected for amplification and sequencing in three random samples from all study populations. Sequence amplification and analysis were conducted according to [27] and sequenced via Macrogen Inc. (Seoul, Korea). SEQUencher 5.0 (Genecodes Corp., Ann Arbor, MI, USA) was used to edit miscalls and to align and trim sequences. All four cpDNA regions were concatenated in MESQUITE 3.04 [28] to a total sequence length of $2457 \mathrm{bp}$, and two indels were identified and coded. Chloroplast haplotypes were identified using DNASP 5.1.1 [29]).

(a)

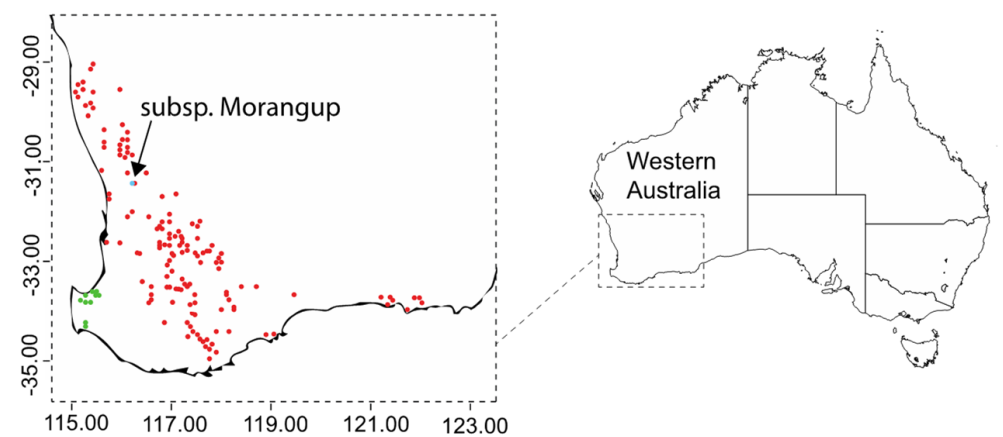

(b)

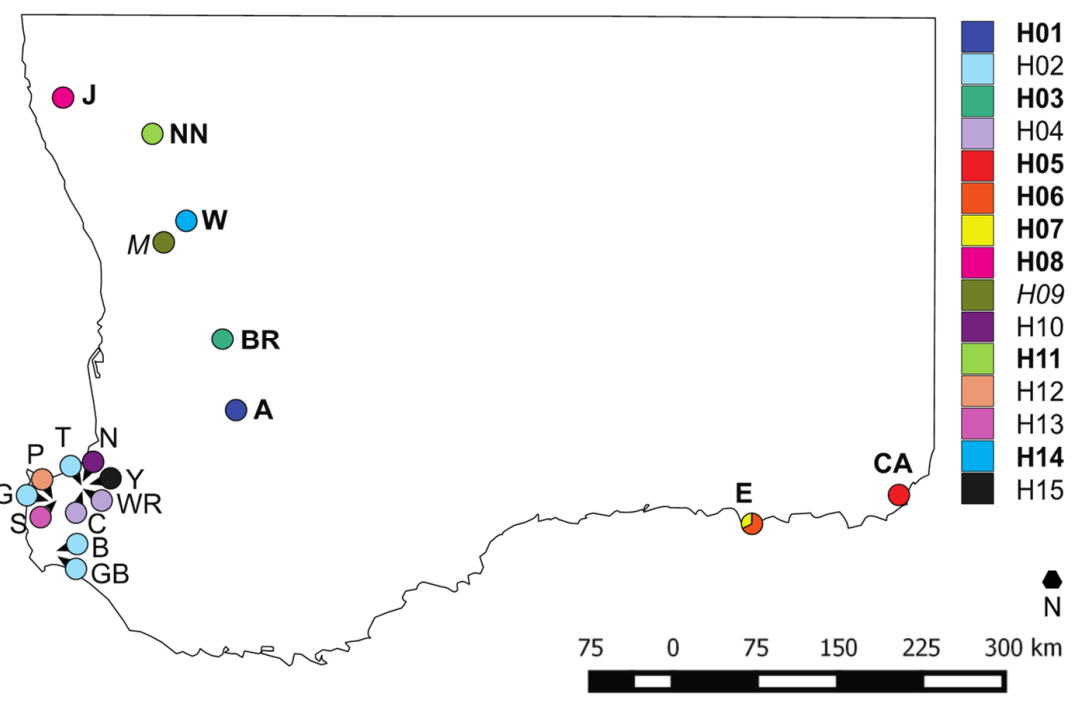

Figure 1. Map showing: (a) the distribution of Banksia nivea in southwestern Australia. Dots indicate the locations of known populations based on records of the Atlas of Living Australia [30]. Subspecies indicated by color; red, subsp. nivea; green, subsp. uliginosa; blue, subsp. Morangup. (b) Distribution of cpDNA ( $p s b \mathrm{~A}-\operatorname{trn} \mathrm{H}, \mathrm{ndhF}$, trnV, and trnQ-rps16) haplotypes overlaid on a geographical map of sampling sites. Pie charts show the proportion of sampled individuals with a given haplotype. 
Genotypes at 10 nuclear microsatellites were determined in seven subsp. nivea, one subsp. Morangup, and seven subsp. uliginosa populations (Table 1). Microsatellite loci were amplified as previously described [23,31]. One additional microsatellite locus was also amplified: DnB003; forward primer sequence $5^{\prime}$-AAGCCCAATATGACCAATAACC-3' and reverse primer sequence $5^{\prime}$-GTCGGCTATATGACTGCATCAC-3'. Modifications to the cited methods were made for $\mathrm{MgCl}_{2}$ concentration and adjusted to $1.5 \mathrm{mM}$ for DnC010 and $1.0 \mathrm{mM}$ for DnB003.

Table 1. Diversity statistics based on 10 nuclear microsatellite loci for populations of Banksia nivea from south-western Australia.

\begin{tabular}{ccccccc}
\hline Subspecies/Pop & $N$ & $A$ & $A_{\mathbf{R}}$ & $\boldsymbol{H}_{\mathbf{O}}$ & $U_{\mathbf{e}}$ & $\boldsymbol{H}_{\mathbf{e}}$ \\
\hline Subsp. nivea & & & & & & \\
J & $19.900(0.100)$ & $3.900(0.994)$ & $2.080(0.273)$ & $0.351(0.081)$ & $0.374(0.083)$ & $0.036(0.045)$ \\
NN & $19.600(0.400)$ & $5.800(0.663)$ & $3.070(0.294)$ & $0.498(0.085)$ & $0.627(0.081)$ & $0.185(0.087) *$ \\
W & $18.100(0.737)$ & $6.700(0.831)$ & $3.370(0.273)$ & $0.566(0.070)$ & $0.697(0.058)$ & $0.173(0.072)^{*}$ \\
BR & $19.100(0.605)$ & $6.700(1.146)$ & $3.120(0.344)$ & $0.435(0.085)$ & $0.625(0.068)$ & $0.248(0.118)^{*}$ \\
A & $17.900(0.623)$ & $8.300(1.126)$ & $3.640(0.340)$ & $0.462(0.073)$ & $0.714(0.069)$ & $0.281(0.105)^{*}$ \\
E & $3.300(0.578)$ & $2.300(0.496)$ & $12.630(0.285)$ & $0.363(0.098)$ & $0.409(0.103)$ & $-0.046(0.098)$ \\
CA & $10.000(0.000)$ & $3.500(0.734)$ & $2.300(0.367)$ & $0.350(0.107)$ & $0.404(0.102)$ & $0.101(0.098)$ \\
Mean & $15.414(0.107)$ & $5.314(0.092)$ & $4.316(0.015)$ & $0.432(0.005)$ & $0.550(0.007)$ & $0.140(0.009)^{*}$ \\
Subsp. Morangup & & & & & \\
M & $19.100(0.605)$ & $5.300(0.932)$ & $2.840(0.321)$ & $0.433(0.089)$ & $0.574(0.083)$ & $0.185(0.117)$ \\
Subsp. uliginosa & & & & & \\
N & $18.900(0.100)$ & $3.800(0.533)$ & $2.210(0.215)$ & $0.401(0.064)$ & $0.441(0.073)$ & $0.018(0.084)$ \\
T & $17.600(0.933)$ & $4.100(0.640)$ & $2.620(0.283)$ & $0.510(0.071)$ & $0.548(0.074)$ & $0.009(0.070)$ \\
Y & $10.400(0.306)$ & $3.000(0.365)$ & $2.080(0.267)$ & $0.335(0.072)$ & $0.366(0.086)$ & $-0.036(0.076)$ \\
C & $18.000(1.022)$ & $4.700(0.667)$ & $2.810(0.239)$ & $0.472(0.066)$ & $0.593(0.058)$ & $0.164(0.097)$ \\
G & $14.800(2.489)$ & $3.400(0.653)$ & $8.330(0.245)$ & $0.452(0.077)$ & $0.498(0.086)$ & $0.029(0.047)$ \\
GB & $11.400(0.909)$ & $4.100(0.605)$ & $2.650(0.279)$ & $0.448(0.065)$ & $0.553(0.074)$ & $0.107(0.071)$ \\
B & $15.800(1.245)$ & $4.300(0.517)$ & $2.740(0.264)$ & $0.404(0.051)$ & $0.582(0.067)$ & $0.195(0.116)$ \\
Mean & $15.271(0.292)$ & $3.914(0.040)$ & $3.349(0.009)$ & $0.432(0.003)$ & $0.511(0.004)$ & $0.069(0.008)$ \\
Total mean & $15.593(0.441)$ & $4.660(0.227)$ & $3.766(0.744)$ & $0.432(0.020)$ & $0.534(0.021)$ & $0.117(0.024)$ \\
\hline
\end{tabular}

$N$, mean sample size per locus; $A$, mean number of alleles per locus; $A_{\mathrm{R}}$ allele number adjusted by rarefaction; $H_{\mathrm{O}}$ observed heterozygosity; $U H_{\mathrm{e}}$, unbiased expected heterozygosity; $F$, Wright's Inbreeding coefficient; standard errors in parentheses; * Significantly different from zero, $p<0.05$.

Microsatellite loci were separated on an Applied Biosystems (Foster City, CA, USA) 3730 capillary sequencer, and 260 individuals (115 subsp. nivea, 20 subsp. Morangup, and 125 subsp. uliginosa) were genotyped using GENEMAPPER version 5.0 (Applied Biosystems, Foster City, CA, USA). Tests for stutter bands, large allele dropout, and null alleles were conducted using MICROCHECKER 2.2.3 [32]. Tests of linkage disequilibrium among pairs of loci were performed with GENEPOP 4.2 [33].

\subsection{Chloroplast DNA Diversity and Relatedness}

We used ARLEQUIN 3.5.2.2 [34] to estimate cPDNA genetic diversity as nucleotide diversity $(\pi)$, haplotype diversity $\left(H_{\mathrm{D}}\right)$, population differentiation as $F_{\mathrm{ST}}$, and differentiation between subspecies (global and pairwise) as $F_{\mathrm{ST}}$ using pooled data. Partitioning of diversity between subspecies, populations within subspecies, and within populations was examined by analysis of molecular variance (AMOVA). Estimates of population differentiation $\left(G_{S T}\right.$, $\left.N_{\mathrm{ST}}\right)$ and presence of phylogeographical structure $\left(N_{\mathrm{ST}}>G_{\mathrm{ST}}\right)$ were estimated using PerMUT 2.0 [35]. If $N_{\mathrm{ST}}$ is significantly greater than $G_{\mathrm{ST}}$, haplotypes within populations are more likely to be closely related than haplotypes among populations.

In ARLEQUIN, tests for neutrality and population expansion were estimated using Tajima's $D$ [36] and Fu's $F_{\mathrm{s}}$ [37], and mismatch distribution analyses were also made to infer spatial and demographic history. Goodness-of-fit to models of spatial or demographic expansion were tested with Harpending's raggedness index $\left(H_{\mathrm{Rag}}\right)$ and the sum of squared 
differences (SSD). These models test the deviation of observed values from distributions expected under population expansion.

To examine the evolutionary relatedness of chloroplast haplotypes, we constructed a median-joining maximum parsimony (MJMP) network in NETWORK 5.0 [38].

\subsection{Nuclear SSR Diversity and Structure}

We measured nSSR genetic variation for each subspecies as mean multi-locus parameters per population (number of alleles per locus, $A$; observed heterozygosity, $H_{\mathrm{o}}$, unbiased expected heterozygosity, $U H_{\mathrm{e}}$; Wright's inbreeding coefficient, $F$ ) using GENALEX v6.501 [39], and as allele number adjusted by rarefaction AR using HP-RARE [40]. We compared parameters between species using ANOVA.

We measured overall differentiation among populations $\left(F_{\mathrm{ST}}\right)$ using FrEENA with and without the Excluding Null Alleles method (ENA) that corrects for null alleles, with 1000 bootstraps to generate $95 \%$ confidence intervals [41]. Partitioning of diversity between subspecies, populations within subspecies, and within populations was examined by analysis of molecular variance (AMOVA) in GENALEx v6.501 [39]. We also estimated global and pairwise differentiation between populations and between subspecies from pooled data as $F_{\mathrm{ST}}$ using GENALEX with statistical testing by random permutations. We used a Mantel procedure to test for a correlation between $\log _{10}$ pairwise geographic distances and linearized pairwise genetic distances estimated in GENALEX.

Genetic structure was examined using both direct phenetic and model-based Bayesian analyses. For phenetic analysis, we used PHYLIP 3.69 [42] to construct an unrooted neighbor-joining (NJ) tree based on CS Chord genetic distance calculated in MSA 4.05 [43] with clustering patterns validated with 1000 bootstraps. For Bayesian analyses, we used STRUCTURE 2.3.4 [44] to identify genetically similar clusters $(K)$ and the proportions of individuals' genotypes belonging to clusters $(q)$. To identify the optimum number of clusters $(K)$ and the likelihood of sub-clusters, we used both the $\Delta K$ statistic of [45] and the median of estimated Ln probabilities of $K$ values using CLUMPAK [46]. Two or more optimal $K$ may be found if samples are taken from hierarchically structured groups such as species containing subspecies ([45,47]. We, therefore, used hierarchical analyses for (1) all samples and (2) two identified population groups (subsp. nivea together with subsp. Morangup, and subsp. uliginosa separate). We ran 20 replicates with a burn-in of 100,000 with 500,000 iterations for Markov chain Monte Carlo parameters for $K=1-15$ possible clusters. We used parameter recommendations [47] including no prior knowledge, the alternative ancestry before separate alphas for each population, an initial ALPHA value of 0.1 , and the correlated allele frequency models.

\section{Results}

\subsection{Chloroplast Diversity and Divergence}

The concatenated, aligned cpDNA sequence data ( $2457 \mathrm{bp})$ revealed 15 haplotypes from 54 individuals from 18 populations: eight haplotypes from subsp. nivea, one from subsp. Morangup, and six from subsp. uliginosa (Figure 1). Only one population had more than one haplotype; a subsp. nivea population (E) was found near the eastern margin of the species' distribution (Figure 1b) with two H06 samples, and one H07 sample. No haplotypes were found in more than one subspecies (Figure 1b) and there was no haplotype diversity in subsp. Morangup. Within the population, haplotype diversity was very low, and most haplotypes were population-specific (86.7\%) although two haplotypes were found in multiple subsp. uliginosa populations (Figure 1b). Measures of haplotype diversity were therefore high overall, and high in subsp. nivea, although lower, although not significantly so, in subsp. uliginosa (Table 2). Nucleotide diversity was very low overall and within subspecies. Estimates of overall population differentiation were very high $\left(F_{\mathrm{ST}}=0.992, G_{\mathrm{ST}}=0.961\right.$; Table 2$)$. Tests revealed significant phylogenetic structure in subsp. nivea $\left(N_{\mathrm{ST}}>G_{\mathrm{ST}}\right)$ but not in subsp. uliginosa or overall. AMOVA indicated there was significant differentiation among subspecies $(23.42 \%)$ although most variation was 
between populations $(75.82 \%)$ with a very small proportion $(0.76 \%)$ within populations (Table 3). Pooled pairwise differentiation was highest for subsp. uliginosa compared to subsp. Morangup $\left(F_{\mathrm{ST}}=0.678\right)$. Differentiation between subsps. nivea and Morangup $\left(F_{\mathrm{ST}}=0.225\right)$, and between subsps. nivea and uliginosa $\left(F_{\mathrm{ST}}=0.270\right)$ were lower and similar. This pattern reflects the prevalence of population-specific haplotypes and singlehaplotype populations.

Table 2. Diversity statistics, tests of neutrality, and mismatch analyses based on sequences $p s b \mathrm{~A}-\operatorname{trn} \mathrm{H}$, $\mathrm{ndhF}, \operatorname{trnV}$, and trnQ-rps16 of chloroplast intergenic spacers regions in Banksia nivea.

\begin{tabular}{|c|c|c|c|c|}
\hline & Total & Subsp. nivea & Subsp. uliginosa & Subsp. Morangup \\
\hline Populations $(n)$ & 18 & 7 & 10 & 1 \\
\hline Haplotypes $(n)$ & 15 & 8 & 6 & 1 \\
\hline Haplotype diversity $H_{\mathrm{D}}$ & $0.920(0.020)$ & $0.910(0.026)$ & $0.786(0.053)$ & 0 \\
\hline Nucleotide diversity $\pi$ & $0.003(0.002)$ & $0.005(0.003)$ & $0.001(0.001)$ & 0 \\
\hline Population differentiation (unordered) $G_{\mathrm{ST}}$ & $0.961(0.039)$ & $0.905(0.095)$ & 1 & - \\
\hline Population differentiation (ordered) $N_{\mathrm{ST}}$ & $0.992(0.008)$ & $0.982(0.018)$ & 1 & - \\
\hline Phylogenetic structure $\left(N_{\mathrm{ST}}>G_{\mathrm{ST}}\right)$ & NS & $p<0.01$ & NS & - \\
\hline Tajima's $D$ & $-0.56 p=0.33$ & $0.16 p=0.61$ & $0.14 p=0.59$ & - \\
\hline $\mathrm{Fu}$ 's $F_{\mathrm{S}}$ & $1.13 p=0.70$ & $4.67 p=0.98$ & $1.62 p=0.77$ & - \\
\hline \multirow{3}{*}{ Demographic expansion } & $\begin{array}{c}\text { SSD 0.010 } \\
p=0.61\end{array}$ & $\begin{array}{c}\text { SSD 0.034, } \\
p=0.12\end{array}$ & $\begin{array}{c}\text { SSD 0.257 } \\
p=0.38\end{array}$ & - \\
\hline & $\begin{array}{c}H_{\text {Rag }} 0.021 \\
p=0.43\end{array}$ & $\begin{array}{c}H_{\text {Rag }} 0.045 \\
p=0.17\end{array}$ & $\begin{array}{c}H_{\text {Rag }} 0.093 \\
p=0.25\end{array}$ & - \\
\hline & $\begin{array}{l}\text { SSD 0.009 } \\
p=0.74\end{array}$ & $\begin{array}{c}\text { SSD 0.032, } \\
p=0.20\end{array}$ & $\begin{array}{c}\text { SSD 0.022 } \\
p=0.50\end{array}$ & - \\
\hline Spatial expansion & $\begin{array}{c}H_{\text {Rag }} 0.021, \\
p=0.56\end{array}$ & $\begin{array}{l}\text { HRag } 0.045 \\
\quad p=0.26\end{array}$ & $\begin{array}{c}H_{\text {Rag }} 0.093 \\
p=0.52\end{array}$ & - \\
\hline
\end{tabular}

Standard deviations are in parentheses. SSD $=$ sum of squared differences. $H_{\text {Rag }}=$ Harpending's raggedness index. NS = not significant.

Table 3. Analysis of molecular variance (AMOVA) of Banksia nivea subspecies based on chloroplast haplotypes and nuclear microsatellite loci.

\begin{tabular}{ccccc}
\hline Source of Variation & d.f. & SS & Variance Component & \% Variation \\
\hline Chloroplast haplotypes & & & & \\
Among subspecies & 2 & 27.6 & 0.569 & 23.42 \\
Among populations within subspecies & 15 & 83.2 & 1.842 & 75.82 \\
Within populations & 36 & 0.7 & 0.019 & 0.76 \\
Nuclear microsatellites & & & & \\
Among subspecies & 2 & 127.3 & 0.126 & 3.0 \\
Among populations within subspecies & 12 & 481.5 & 1.100 & 26.7 \\
Within populations & 505 & 1463.2 & 2.897 & 70.3 \\
\hline
\end{tabular}

The haplotype network was an asymmetrical star structure and contained two closed loops indicative of homoplasy (Figure 2). One side of the network corresponds to subsps. nivea and Morangup and showed longer branches with more divergent haplotypes connected through the H01 haplotype to weakly diverged haplotypes found in subsp. uliginosa. The haplotype found in subsp. Morangup was divergent but no more so than other haplotypes from subsp. nivea. Only H01 was inferred to give rise to several other haplotypes. Therefore, there was a weak geographical pattern concordant with the taxonomy of the described subspecies with haplotypes from subsp. uliginosa found in the southwest of the species' range is closely related to haplotypes from subsp. nivea from the central part of the species range. 


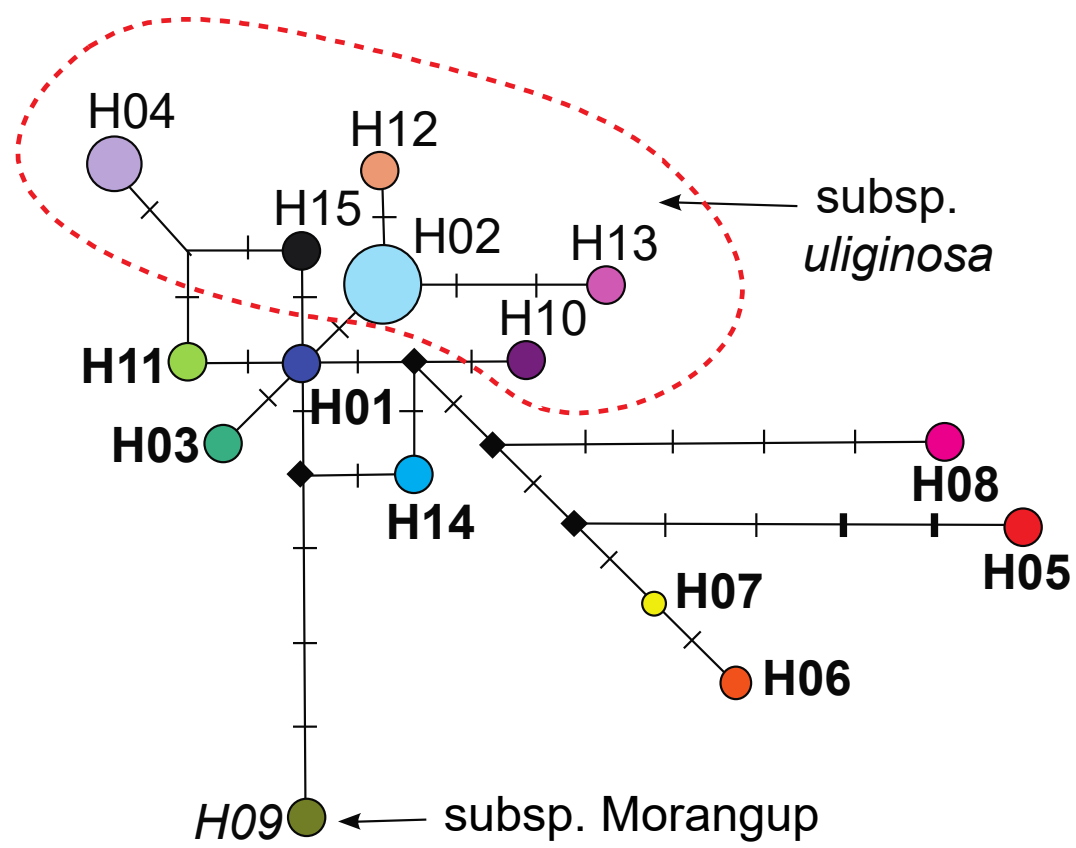

Figure 2. Median-joining maximum parsimony (MJMP) network of chloroplast haplotypes observed in Banksia nivea from south-western Australia. Circle sizes are proportional to haplotype frequency among samples. Black dashes represent a single nucleotide substitution (not bold) or indel (bold). Black boxes represent inferred unsampled haplotypes. Haplotype numbers and colors correspond to those in Figure 1.

Estimates of neutrality (Tajima's $D, F u^{\prime} s F_{\mathrm{s}}$ ) that can predict population size changes were not significant for either the species overall or for the separate subspecies (Table 2). However, mismatch analysis revealed evidence of demographic and spatial expansion, both overall and for subsp. nivea and uliginosa separately, as SSD and $\mathrm{H}_{\mathrm{RAG}}$ values that did not deviate from models of sudden expansion (Table 2). Non-significant $p$-values do not deviate from the null model and therefore support an expansion scenario.

\subsection{Nuclear Diversity and Structure}

No evidence of stutter or large allele dropout was detected for nSSR loci and there was no evidence of significant linkage disequilibrium. We detected significant frequencies of null alleles at four loci (DnA011, DnC010, DnB003, and DnD007) but a comparison of $F_{\text {ST }}(95 \% \mathrm{CI})$ estimates with and without ENA adjustment (reported here) showed that null alleles did not cause significant bias and therefore loci were not excluded from analyses.

The average number of alleles per population was low (2.3-8.3; Table 1) even after rarefaction (2.3-12.63). Other diversity measures were moderate and although levels were generally lower in subsp. uliginosa than in subsp. nivea, there were no significant differences between subspecies. Significant inbreeding was not detected in subsp. uliginosa or Morangup although Wright's inbreeding coefficients $(F)$ were positive and significant in four of seven populations of subsp. nivea (NN, W, BR, A; Table 1).

Genetic differentiation was high overall $\left(F_{\mathrm{ST}}=0.306\right)$. Differentiation levels between populations within subspecies were similar (ssp. nivea $F_{\mathrm{ST}}=0.254$; ssp. uliginosa $F_{\mathrm{ST}}=0.295$ ). Partitioning by AMOVA found only a small amount of variation between subspecies (3\%; Table 3). Most variation was within populations (70.3\%) with $26.7 \%$ between populations. This is reflected in low pooled global differentiation among subspecies $\left(F_{\mathrm{ST}}=0.095\right)$. Pairwise pooled comparisons showed the highest differentiation between subsp. Morangup and uliginosa $\left(F_{\mathrm{ST}}=0.178\right)$, while differentiation between subsp. nivea and both Morangup $\left(F_{\mathrm{ST}}=0.094\right)$ and uliginosa $\left(F_{\mathrm{ST}}=0.082\right)$ was lower and similar.

The phenetic analysis showed separation of subsp. nivea and subsp. uliginosa populations that, although weak, was concordant with taxonomy while subsp. Morangup 
was nested within subsp. nivea (Figure 3a). Grouping was not strong except for the most northern $(\mathrm{J}, \mathrm{NN})$ and most south-western (B, GB) populations. There was a significant signal of increasing genetic distance with geographic distance (IBD) across all populations $\left(r^{2}=0.128, p<0.05\right)$ and also within subspecies (subsp. nivea, $r^{2}=0.296, p<0.01$; subsp. uliginosa, $\left.r^{2}=0.308, p<0.05\right)$.

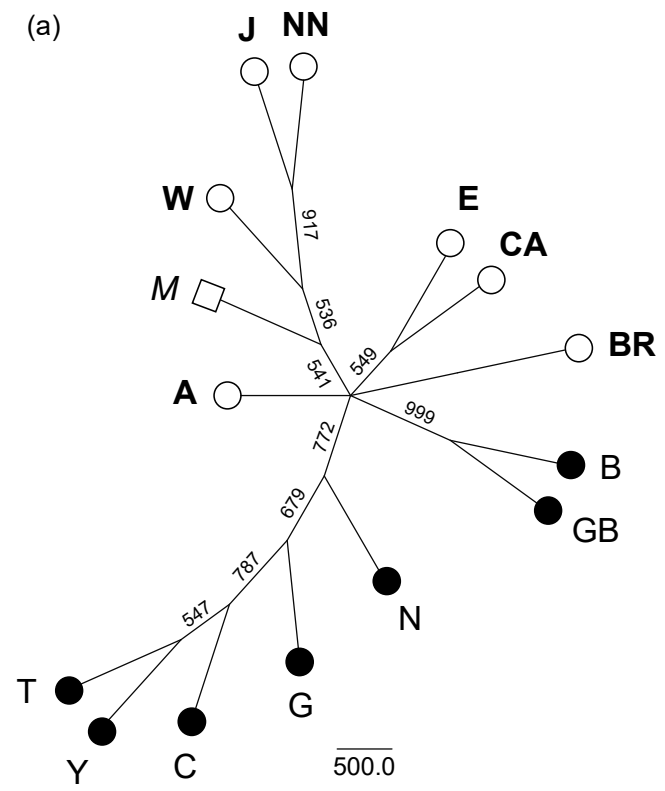

(b)

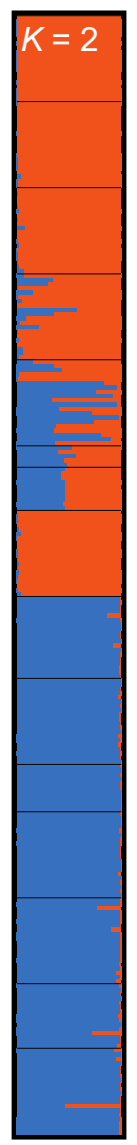

(c)

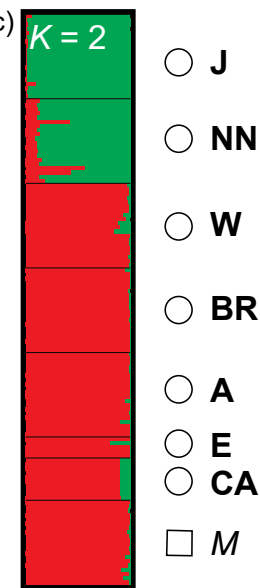

(d)

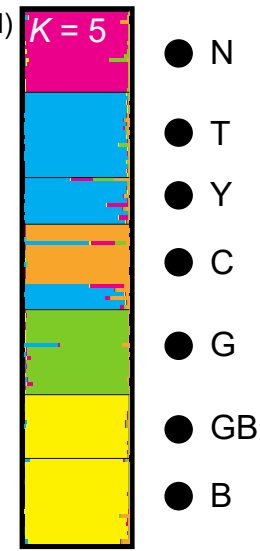

Figure 3. The genetic structure of sampled populations of Banksia nivea in south-western Australia, based on individual nuclear microsatellite genotypes. (a) A neighbor-joining (NJ) tree of CS Chord distance. Support is shown on the branches as the number of bootstraps out of 1000 . Values $>500$ are shown. (b-d) Bar graphs inferred using Bayesian assignment in STRUCTURE 2.3.4 showing (b) structure at $K=2$ for all subspecies (c) structure at $K=2$ for subspecies nivea and Morangup, and (d) structure at $K=5$ for subspecies uliginosa. Each individual is represented as a single line with colored segments representing the proportion of ancestry from $k$ clusters $(q)$. Results are the optimal alignment of replicates.

At the highest level, STRUCTURE analysis identified an optimum of two genetic clusters (Figure 3b) that reflected a geographic pattern and were partly aligned with the morphological subsp. nivea and uliginosa. As in the distance-based analysis, subsp. Morangup clustered with subsp. nivea. Admixture was evident in populations in the geographically central (A and BR) and eastern (CA, E) range while populations in the far north and south-west were more clearly differentiated. This may reflect IBD in the center of the range. At a lower level of structure, clusters reflected populations or groups of geographically proximal populations (Figure 3c).

\section{Discussion}

Patterns of genetic variation between subsp. nivea and uliginosa were concordant with the current taxonomy, while subsp. Morangup could not be distinguished from 
subsp. nivea in this study. Phylogeographic analyses suggested divergence of subspecies may have been associated with expansion into the southwest corner of Western Australia, a biogeographic area characterized by different substrates, climate, and vegetation. As predicted, patchy abundance was associated with high differentiation between populations and low to moderate nuclear variation reflecting the impact of small population size and restrictions to gene flow. Although genetic diversity was generally lower in the localized subsp. uliginosa than in the widespread subsp. nivea, differences associated with range were not significant, contrary to expectations based on meta-analysis across Australian plants [25]. This may be due to the stronger effects of patchy distribution in both subspecies.

\subsection{Distinction between Subspecies}

The morphological differentiation of allopatric subsp. nivea and uliginosa were reflected in patterns of cpDNA and nuclear microsatellite variation, while subsp. Morangup was not genetically differentiated from subsp. nivea. Evolutionary forces act on phenotypic traits differently from neutral genetic markers, and thus morphological divergence is not always associated with genomic divergence. Subspecies have traditionally been defined as phenotypically distinct, allopatric sets of populations that may intergrade at geographic boundaries $[2,3]$ and are widely adopted in plant taxonomy, primarily using geographical and ecological differences to distinguish them [4]. Given the lack of genetic differentiation, we suggest a review of the morphological variation in subsp. Morangup compared to subsp. nivea is required to inform a taxonomic revision. A review of approaches to dealing with species-population continuums of genetic diversity for conservation in the age of genomics [1] proposed that, although they may not represent historically isolated populations and satisfy criteria for Evolutionarily Significant Units (ESUs), the recognition of phenotypically defined subspecies may be warranted.

Although differentiated by patterns in the haplotype network and structure plots of nuclear variation, the divergence between subsp. nivea and uliginosa was not strong. Investigations into congruence between genetic structure and morphological variation in widespread plant species in the SWAFR vary. For example, studies of two widespread and morphologically variable species complexes, Melaleuca uncinata R.Br. [48] and Calothamnus quadrifidus R.Br. [49] have found general agreement between morphological variation and genetic structure. In contrast, deep lineage divergence in B. sessilis [12] was not aligned with morphological varieties and was associated with differences in habitat and substrate.

\subsection{Biogeographic Expansion}

Differentiation of subsp. nivea and uliginosa was consistent with other genetic and phylogeographic studies in Australian plants that have identified distinct lineages that reflect the geological and edaphic complexities of habitats that vary in terms of vegetation and climate $[14,17,25]$. In B. nivea, the patterns of geographic separation in different habitats (dry sandy soils contrasting with winter-wet ironstone soils), combined with haplotype diversity and morphological differences provide support for hypotheses of divergence driven by expansion into a different biogeographic area. Both subsp. nivea and uliginosa showed high haplotype diversity with low nucleotide diversity, signals of expansion, and a phylogeographic pattern consistent with subspecies differentiation. The phylogeographic structure was also observed in the more widespread subsp. nivea. These traits suggest that diversification associated with geographic isolation and habitat specificity are likely to have contributed to the divergence of subspecies following expansion into the distinct southwest Australian ironstone habitat. A similar scenario was proposed [49] for another ironstone endemic, the woody shrub Calothamnus quadrifidus subsp. teretifolius A.S. George \& N. Gibson, which does not share haplotypes with other subspecies of C. quadrifidus found outside the ironstone habitat. Similar genetic differentiation of populations occurring in the specific ironstone habitat has also been observed in Hakea oldfieldii Benth. [50]. Expansion to occupy habitats with different substrate likely leads to differentiation through adaptation, 
and divergence associated with substrate has also been identified in other species in different ecosystems, e.g., [9-12].

In $B$ nivea, a more ancient origin for subsp. nivea compared to subsp. uliginosa is suggested by higher diversity and mutational divergence of haplotypes compared to subsp. uliginosa. This would be consistent with branching patterns in the dryandra clade of the Banksia phylogeny [19]. Although major spatial contraction-expansion dynamics appear to have been rare in the mesic biota of Australia [51,52], range expansions have been associated with acceleration of the progressive drying of mesic environments that began in the late Pliocene (c. 3 Mya) $[52,53]$. Range expansions have also been associated with the southward progress of increasing aridity in the SWAFR from the mid-Pleistocene that opened up habitats within the wetter forests allowing for the expansion of species to these areas $[49,54,55]$. Expansion and divergence in B. nivea are consistent with this pattern providing another example of expansion among widespread, woody shrubs. Indeed, the pattern of southwestern expansion, as reflected in haplotype network relationships and divergence, is most similar to that found in the widespread wind-pollinated shrub, the dwarf sheoak Allocasuarina humilis (Otto \& A. Dietr.) L.A.S. Johnson [54], although on a smaller scale. This phylogeographic pattern in A. humilis was also best explained by south-west expansion from populations with a more ancient history of persistence in dry shrublands (300-600 $\mathrm{mm}$ year $^{-1}$ ) into areas previously occupied by higher rainfall forests (600-1400 $\mathrm{mm}$ year $\left.^{-1}\right)$ as the climate dried progressively from the late Miocene [54].

\subsection{Contemporary Genetic Diversity and Population Structure}

Many reviews of nuclear genetic variation have found that genetic structure is influenced by mating systems, life-history traits, chromosomal variation, population distribution, and other ecological traits related to gene flow [7,56-59]. A specific analysis of diversity and population differentiation in the Australian flora [25] found strong associations with abundance, where patchy populations were significantly associated with low diversity and high differentiation. We found patterns consistent with this in B. nivea but, contrary to the strong association also expected for range and diversity, both localized and widespread subspecies of B. nivea had diversity levels that are expected for localized species. Over the widespread distribution of the species, low to moderate nuclear genetic diversity and moderate to high differentiation among populations is not unexpected. Patchy populations are often small, and population genetic theory predicts they may be prone to genetic drift and inbreeding leading to loss of genetic diversity and differentiation $[56,60]$. We found no significant evidence of drift or bottlenecks in B. nivea, although our ability to detect these impacts was limited by sample size. We did identify significant inbreeding in this study in some populations of subsp. nivea but not in subsp. uliginosa. More detailed studies of the mating system in subsp. uliginosa showed high outcrossing $(95 \%)$ and little relatedness amongst adult plants within populations [23], and high production of seeds that was unaffected by population size [20].

Analysis of contemporary genetic relationships revealed evidence of restricted gene flow between populations across the species' range with geographic clustering, high pairwise $F_{\mathrm{ST}}$ values, a significant proportion of genetic variation apportioned between populations, and significant IBD. We detected a genetic pattern in cluster analysis and in the distance-based tree that related to the current subspecies taxonomy and different biogeographic areas. This, together with significant IBD, is likely to reflect restricted gene flow across heterogeneous landscapes. Cluster analysis also detected a geographic pattern in genetic sub-structuring within both subsp. nivea and uliginosa that are likely to reflect gene flow patterns. Gene flow via pollen dispersal is achieved in Banksia species by birds, mammals, and insects [61,62]. Specific pollinators for B. nivea have not been determined and it is likely pollination is achieved primarily by small non-flying mammals that move within a small range $(<30 \mathrm{~m})$, even over several months, and are likely to achieve nearneighbor pollination, and by birds such as honeyeaters that are likely to facilitate some longer distance pollen dispersal between local populations. In a study on pollinators in 
subsp. uliginosa [20] treatments open to birds and mammals produced high levels of fruit compared to those open to invertebrates only or closed to all pollinators, and treatments open to all pollinators produced 39\% more fruit than those open to mammals but not birds. Effective pollination was also shown in a study of the mating system that found high levels of outcrossing (95\%), and up to $30 \%$ of progeny produced in seed crops was attributed to mating with fathers outside small patchy populations likely due to bird pollination [23]. Unusually for Banksia, seeds of B. nivea have adaptations for dispersal, and the sharing of seed-dispersed haplotypes among geographically close subsp. uliginosa populations may reflect some localized inter-population dispersal, although this is difficult to distinguish from co-ancestry among local populations. The significant differentiation among populations and the biogeographic structure observed in $B$. nivea likely reflects generally localized pollen dispersal associated with habitat specificity of the predominant non-flying mammal pollinators [20,23], along with generally short-range gene dispersal by seeds.

\section{Conclusions}

Analysis of genetic relationships among the three subspecies of $B$. nivea in southwestern Australia supported the current taxonomy of subspecies nivea and uliginosa, and indicated clarification of the morphological traits and heritability in subsp. Morangup is warranted. The climatic history of the SWAFR appears to have had a significant influence on the genetic divergence within $B$. nivea. We found patterns of variation consistent with expansion into a new biogeographical area and onto different substrate followed by divergence into lineages concurrent with the taxonomic subspecies. The pattern of nuclear DNA diversity and differentiation likely reflects the influence of distribution and restricted gene flow between small and patchy populations.

Author Contributions: Conceptualization, M.B.; methodology, M.B. and J.S.; formal analysis, J.S.; writing — original draft preparation, J.S.; writing—review and editing, J.S. and M.B.; visualization, J.S. All authors have read and agreed to the published version of the manuscript.

Funding: This research received no external funding.

Data Availability Statement: The data presented in this study are available on request from the corresponding author. The data are not publicly available due to legislative protection for threatened species.

Acknowledgments: We thank Sarah Tapper, Ashney Shah, Shelley McArthur, Bronwyn Macdonald, and Margaret Hankinson for laboratory assistance. We thank Neil Gibson and Colin Yates for their assistance in the field and discussion on the biology of Banksia nivea and the habitat specialization of the flora.

Conflicts of Interest: The authors declare no conflict of interest.

\section{References}

1. Coates, D.J.; Byrne, M.; Moritz, C. Genetic diversity and conservation units: Dealing with the species-population continuum in the age of genomics. Front. Ecol. Evol. 2018, 6, 165. [CrossRef]

2. Mayr, E. Systematics and the Origin of Species; Columbia University Press: New York, NY, USA, 1942.

3. Grant, V. Plant Speciation; Columbia University Press: New York, NY, USA, 1981.

4. Hamilton, C.; Reichard, S. Current practice in the use of subspecies, variety, and forma in the classification of wild plants. Taxon 2019, 41, 485-498. [CrossRef]

5. Duminil, J.; Kenfack, D.; Viscosi, V.; Grumiau, L.; Hardy, O.J. Testing species delimitation in sympatric species complexes: The case of an African tropical tree, Carapa spp. (Meliaceae). Mol. Phylogenet. Evol. 2012, 62, 275-285. [CrossRef] [PubMed]

6. Christmas, M.J.; Biffin, E.; Lowe, A.J. Measuring genome-wide genetic variation to reassess subspecies classifications in Dodonaea viscosa (Sapindaceae). Aust. J. Bot. 2018, 66, 287-297. [CrossRef]

7. Ellstrand, N.C. Is gene flow the most important evolutionary force in plants? Am. J. Bot. 2014, 101, 737-753. [CrossRef]

8. Wang, I.J.; Bradburd, G.S. Isolation by environment. Mol. Ecol. 2014, 23, 5649-5662. [CrossRef] 
9. Zhang, Y.-H.; Wang, I.J.; Comes, H.P.; Peng, H.; Qiu, Y.-X. Contributions of historical and contemporary geographic and environmental factors to phylogeographic structure in a Tertiary relict species, Emmenopterys henryi (Rubiaceae). Sci. Rep. 2016, 6, 24041. [CrossRef]

10. Robins, T.P.; Binks, R.M.; Byrne, M.; Hopper, S.D. Contrasting patterns of population divergence on young and old landscapes in Banksia seminuda (Proteaceae), with evidence for recognition of subspecies. Biol. J. Linn. Soc. 2021, 133, 449-463. [CrossRef]

11. Moore, A.J.; Merges, D.; Kadereit, J.W. The origin of the Serpentine endemic Minuartia larcifolia subsp. ophiolitica by vicariance and competitive exclusion. Mol. Ecol. 2013, 22, 2218-2231. [CrossRef]

12. Nistelberger, H.M.; Tapper, S.L.; Coates, D.J.; McArthur, S.L.; Byrne, M. As old as the hills: Pliocene palaeogeographical processes influence patterns of genetic structure in the widespread, common shrub Banksia sessilis. Ecol. Evol. 2021, 11, 1069-1082. [CrossRef]

13. Byrne, M.; Murphy, D.J. The origins and evolutionary history of xerophytic vegetation in Australia. Aust. J. Bot. 2020, 68, 195-207. [CrossRef]

14. Coates, D.J. Defining conservation units in a rich and fragmented flora: Implications for the management of genetic resources and evolutionary processes in south-west Australian plants. Aust. J. Bot. 2000, 48, 329-339. [CrossRef]

15. Byrne, M.; Coates, D.; Forest, F.; Hopper, S.; Krauss, S.; Sniderman, J.; Thiele, K. A diverse flora-species and genetic relationships In Plant Life on the Sandplains in Southwest Australia, a Global Biodiversity Hotspot; Lambers, H., Ed.; University of Western Australia Publishing: Crawley, WA, USA, 2014; pp. 81-99.

16. Coates, D.J.; McArthur, S.L.; Byrne, M. Significant genetic diversity loss following pathogen driven population extinction in the rare endemic Banksia brownii (Proteaceae). Biol. Conserv. 2015, 192, 353-360. [CrossRef]

17. Sampson, J.F.; Byrne, M.; Yates, C.J.; Gibson, N.; Thavornkanlapachai, R.; Stankowski, S.; Macdonald, B.; Bennett, I. Contemporary pollen-mediated gene immigration reflects the historical isolation of a rare, animal-pollinated shrub in a fragmented landscape. Heredity 2014, 112, 172-181. [CrossRef] [PubMed]

18. Cavanagh, A.K.; Pieroni, M. The Dryandras; Australian Plants Society (SGAP Victoria) Inc.; Wildflower Society of Western Australia Inc.: Melbourne, Australia, 2006.

19. Cardillo, M.; Pratt, R. Evolution of a hotspot genus: Geographic variation in speciation and extinction rates in Banksia (Proteaceae). BMC Evol. Biol. 2013, 13, 155. [CrossRef] [PubMed]

20. Thavornkanlapachai, R.; Byrne, M.; Yates, C.J.; Ladd, P.G. Degree of fragmentation and population size do not adversely affect reproductive success of a rare shrub species, Banksia nivea (Proteaceae), in a naturally fragmented community. Bot. J. Linn. Soc. 2019, 191, 261-273. [CrossRef]

21. George, A. New taxa and a new infrageneric classification in Dryandra R.Br. (Proteaceae: Grevilleoideae). Nuytsia 1996, 10, 313-408.

22. Brown, A.; Thomson-Dans, C.M.N. Western Australia's Threatened Flora; Brown, A., Thomson-Dans, C.M.N., Eds.; Department of Conservation and Land Management: Perth, Australia, 1998.

23. Thavornkanlapachai, R.; Ladd, P.G.; Byrne, M. Population density and size influence pollen dispersal pattern and mating system of the predominantly outcrossed Banksia nivea (Proteaceae) in a threatened ecological community. Biol. J. Linn. Soc. 2018, 124, 492-503. [CrossRef]

24. FloraBase-the Western Australian Flora. Available online: https://florabase.dpaw.wa.gov.au/browse/profile/32205 (accessed on 11 June 2021).

25. Broadhurst, L.; Breed, M.; Lowe, A.; Bragg, J.; Catullo, R.; Coates, D.; Encinas-Viso, F.; Gellie, N.; James, E.; Krauss, S.; et al. Genetic diversity and structure of the Australian flora. Divers. Distrib. 2017, 23, 41-52. [CrossRef]

26. Byrne, M.; Parrish, T.L.; Moran, G.F. Nuclear RFLP diversity in Eucalyptus nitens. Heredity 1998, 81, 225-233. [CrossRef]

27. Byrne, M.; Hankinson, M. Testing the variability of chloroplast sequences for plant phylogeography. Mol. Ecol. Resour. 2012, 60, 569-574. [CrossRef]

28. Maddison, W.P.; Maddison, D.R. Mesquite: A Modular System for Evolutionary Analysis. Available online: http: // mesquiteproject.org (accessed on 2 October 2017).

29. Librado, P.; Rozas, J. DnaSP v.5: A software for comprehensive analysis of DNA polymorphism data. Bioinformatics 2009, 25, 1451-1452. [CrossRef]

30. Atlas of Living Australia. Available online: https://bie.ala.org.au/species/https://id.biodiversity.org.au/node/apni/2894027 (accessed on 16 June 2021).

31. Millar, M.A.; Byrne, M. Characterization of polymorphic microsatellite DNA markers in Banksia nivea, formerly Dryandra nivea. Mol. Ecol. Resour. 2008, 8, 1393-1394. [CrossRef] [PubMed]

32. van Oosterhout, C.; Hutchinson, W.F.; Wills, D.P.M.; Shipley, P. MICRO-CHECKER: Software for identifying and correcting genotyping errors in microsatellite data. Mol. Ecol. Notes 2004, 4, 535-538. [CrossRef]

33. Rousset, F. GENEPOP'007: A complete reimplementation of the GENEPOP software for Windows and Linux. Mol. Ecol. Resour. 2008, 8, 103-106. [CrossRef]

34. Excoffier, L.; Lischer, H. Arlequin Suite Ver 3.5: A new series of programs to perform population genetic analyses under Linux and Windows. Mol. Ecol. Resour. 2010, 10, 464-467. [CrossRef]

35. Pons, O.; Petit, R.J. Measuring and testing genetic differentiation with ordered versus unordered alleles. Genetics 1996, 144, 1238-1245. [CrossRef] 
36. Tajima, F. Statistical methods for testing the neutral mutation hypothesis by DNA polymorphism. Genetics 1989, 123, 585-595. [CrossRef]

37. Fu, Y.X. Statistical tests of neutrality of mutations against population growth, hitchhiking and background selection. Genetics 1997, 147, 915-925. [CrossRef]

38. Bandelt, H.-J.; Forster, P.; Rohl, A. median-joining networks for inferring intraspecific phylogenies. Mol. Biol. Evol. 1999, 16, 37-48. [CrossRef]

39. Peakall, R.; Smouse, P.E. GenALEx 6.5: Genetic analysis in Excel. Population genetic software for teaching and research-an update. Bioinformatics 2012, 28, 2537-2539. [CrossRef] [PubMed]

40. Kalinowski, S.J. HP-RARE 1.0: A computer program for performing rarefaction on measures of allelic richness. Mol. Ecol. Notes 2005, 5, 187-189. [CrossRef]

41. Chapuis, M.P.; Estoup, A. Microsatellite null alleles and estimation of population differentiation. Mol. Biol. Evol. 2007, 24, 621-631. [CrossRef] [PubMed]

42. Felsenstein, J. PHYLIP—phylogeny inference package (Version 3.2). Cladistics 1989, 5, 164-166.

43. Dieringer, D.; Schlötterer, C. Microsatellite Analyser: A platform independent analysis tool for large microsatellite data sets. Mol. Ecol. Notes 2003, 3, 167-169. [CrossRef]

44. Pritchard, J.K.; Stephens, M.; Donnelly, P. Inference of population structure using multilocus genotype data. Genetics 2000, 155, 945-959. [CrossRef] [PubMed]

45. Evanno, G.; Regnaut, S.; Goudet, J. Detecting the number of clusters of individuals using the software STRUCTURE: A simulation study. Mol. Ecol. 2005, 14, 2611-2620. [CrossRef] [PubMed]

46. Kopelman, N.M.; Mayzel, J.; Jakobsson, M.; Rosenberg, N.A.; Mayrose, I. Clumpak: A program for identifying clustering modes and packaging population structure inferences across K. Mol. Ecol. Resour. 2015, 15, 1179-1191. [CrossRef]

47. Wang, J. The computer program Structure for assigning individuals to populations: Easy to use but easier to misuse. Mol. Ecol. Resour. 2017, 17, 981-990. [CrossRef]

48. Broadhurst, L.; Byrne, M.; Craven, L.; Lepschi, B. Genetic congruence with new species boundaries in the Melaleuca uncinata complex (Myrtaceae). Aust. J. Bot. 2004, 52, 729-737. [CrossRef]

49. Nistelberger, H.; Gibson, N.; Macdonald, B.; Tapper, S.-L.; Byrne, M. Phylogeographic evidence for two mesic refugia in a biodiversity hotspot. Heredity 2014, 113, 454-463. [CrossRef] [PubMed]

50. Sampson, J.F.; Hankinson, M.; McArthur, S.; Tapper, S.; Langley, M.; Gibson, N.; Yates, C.; Byrne, M. Long-term "islands" in the landscape: Low gene flow, effective population size and genetic divergence in the shrub Hakea oldfieldii (Proteaceae). Bot. J. Linn. Soc. 2015, 179, 319-334. [CrossRef]

51. Byrne, M. Evidence for multiple refugia at different time scales during Pleistocene climatic oscillations in southern Australia inferred from phylogeography. Quat. Sci. Rev. 2008, 27, 2576-2585. [CrossRef]

52. Byrne, M.; Steane, D.A.; Joseph, L.; Yeates, D.K.; Jordan, G.J.; Crayn, D.; Aplin, K.; Cantrill, D.J.; Cook, L.G.; Crisp, M.D.; et al. Decline of a biome: Evolution, contraction, fragmentation, extinction and invasion of the Australian mesic zone biota. J. Biogeogr. 2011, 38, 1635-1656. [CrossRef]

53. Byrne, M.; Yeates, D.K.; Joseph, L.; Kearney, M.; Bowler, J.; Williams, M.A.J.; Cooper, S.; Donnellan, S.C.; Keogh, J.S.; Leys, R.; et al. Birth of a biome: Insights into the assembly and maintenance of the Australian arid zone Biota. Mol. Ecol. 2008, 17, $4398-4417$. [CrossRef] [PubMed]

54. Llorens, T.M.; Tapper, S.-L.; Coates, D.J.; McArthur, S.; Hankinson, M.; Byrne, M. Does population distribution matter? Influence of a patchy versus continuous distribution on genetic patterns in a wind-pollinated shrub. J. Biogeogr. 2016, 44, 361-374. [CrossRef]

55. Sampson, J.; Tapper, S.; Coates, D.; Hankinson, M.; McArthur, S.; Byrne, M. Persistence with episodic range expansion from the early Pleistocene: The distribution of genetic variation in the forest tree Corymbia calophylla (Myrtaceae) in south-Western Australia. Biol. J. Linn. Soc. 2018, 123, 545-560. [CrossRef]

56. Loveless, M.; Hamrick, J. Ecological determinants of genetic structure in plant populations. Annu. Rev. Ecol. Evol. Syst. 1984, 15, 65-96. [CrossRef]

57. Nybom, H. Comparison of different nuclear DNA markers for estimating intraspecific genetic diversity in plants. Mol. Ecol. 2004, 13, 1143-1155. [CrossRef]

58. Duminil, J.; Fineschi, S.; Hampe, A.; Jordano, P.; Salvini, D.; Vendramin, G.G.; Petit, R.J.; The, S.; Naturalist, A.; May, N. Can population genetic structure be predicted from life-history traits? Am. Nat. 2014, 169, 662-672. [CrossRef]

59. Gitzendanner, M.A.; Soltis, P.S. Patterns of genetic variation in rare and widespread plant congeners. Am. J. Bot. 2000, 87, 783-792. [CrossRef] [PubMed]

60. Ellstrand, N.C.; Elam, D.R. Population genetic consequences of small population size: Implications for plant conservation. Annu. Rev. Ecol. Evol. Syst. 1993, 24, 217-242. [CrossRef]

61. Ford, H.A.; Paton, D.C.; Forde, N. Birds as pollinators of Australian plants. N. Z. J. Bot. 1979, 17, 509-519. [CrossRef]

62. Wooller, R.D.; Russell, E.M.; Renfree, M.B.; Towers, P.A. A comparison of seasonal changes in the pollen loads of nectarivorous marsupials [Tarsipes] and birds [honeyeaters]. Wildl. Res. 1983, 10, 311-317. [CrossRef] 